\title{
WHAT WILL HAPPEN TO NUMBER OF THE INFECTED IF ACCURACY OF THE PCR TEST IMPROVES?
}

\author{
Yasunori Fujita $1 \square$ \\ ${ }^{1}$ Keio University, Japan.
}

Received 17 September 2021

Accepted 18 October 2021

Published 31 October 2021

\section{CorrespondingAuthor}

Yasunori Fujita,

yfujita@econ.keio.ac.jp

DOI

10.29121/granthaalayah.v9.i10.2021 .4305

Funding: This research received no specific grant from any funding agency in the public, commercial, or not-for-profit sectors.

Copyright: (C) 2021 The Author(s). This is an open access article distributed under the terms of the Creative Commons Attribution License, which permits unrestricted use, distribution, and reproduction in any medium, provided the original author and source are credited.

\section{ABSTRACT}

Among the strategies to tackle the COVID-19, much attention is paid to "test and isolation" advocated by Romer (2000), Peto et al (2020) etc., in addition to vaccination and development of medicines to treat COVID-19. According to these articles, what is necessary is a targeted version of lockdown, that is, to test everyone regularly and isolate the small fraction of the population who test positive.

There is, however, concern that the PCR test is not always effective, so that, in the present paper, we investigate the effects of improvement of the PCR test by constructing a simple intertemporal theoretical model. Main result we obtain is that improvement of the PCR test could increase the number of the infected individuals at first, so that we should improve the accuracy of the PCR test much enough to reduce the number of the infected individuals.

Keywords: COVID-19, Accuracy of The PCR Test, Antibody, Steady State Number of The Infected Individuals, Transmission Rate of The Coronavirus

\section{INTRODUCTION}

Among the strategies to tackle the COVID-19, much attention is paid to "test and isolation" advocated by Romer (2020), Peto et al. (2020) etc., in addition to vaccination and development of medicines to treat COVID-19. According to these articles, what is necessary is a targeted version of lockdown, that is, to test everyone regularly and isolate the small fraction of the population who test positive.

There is, however, concern that the PCR test is not always effective, so that, in the present paper, we investigate the effects of improvement of the PCR test by constructing a simple intertemporal theoretical model, extending theoretical models such as Fujita (2020a), Fujita (2020b), Fujita (2020c), Fujita (2021a), Fujita (2021b). The present paper is also inspired by numerous empirical studies, which revealed the impacts of the COVID-19 on various economic aspects such as consumption, stock market, uncertainty, tax policy, leadership styles and so on Baker et al. (2020), Baker et al. (2020), Baker et al. (2020), Watanabe (2020), Bandara and Weerasooriya (2021), Ramadhanti and Kularajasingham (2021). In the present paper, we investigate what will happen to number of the infected if accuracy of the PCR test improves. Different from Fujita (2021a), which analyzed the consequence of prevention measures such as vaccination, and Fujita (2021b), which focused on the treatment of the patients who had positive PCR 
test, the present paper focuses on the improvement of the PCR test by incorporating the antibodies.

Structure of this paper is as follows. Section 2 lays out the basic model and section 3 derives the number of the infected individuals in the steady state. Concluding remarks are made in section 4.

\section{BASIC MODEL}

Let us consider an intertemporal economy where time passes continuously and the time horizon is infinite. The economy consists of $N(>0)$ individuals, of whom $x(t)$ individuals in period $t$ are infected with the coronavirus but do not to present symptoms. We assume that every individual takes the PCR test in every period, which is incomplete in a sense that $p \times 100 \%$ of the infected individuals $x(t)$, i.e., $p x(t)$, are falsely judged to be negative. We also assume that those who tested positive get treatments and are allowed to go out for work, shopping etc., but can be infected again in the same period.

As a characteristic of the present paper, we assume that, in period $t$, among those who are not infected, $\theta p x(t)$ individuals develop antibodies, where $\theta$ is a positive constant, meaning the more the infected individuals, the more individuals develop antibodies.

By assuming each of those who are infected but judged to be negative transmits the virus to $\alpha$ individuals in period $t$, of whom a fraction of $1-\frac{(1+\theta) p x(t)}{N}$ is newly infected since $\frac{p x(t)}{N}$ is infected and $\frac{\theta p x(t)}{N}$ has developed antibody already, we can express the motion of number of the infected individuals as.

$$
x(t+1)=p x(t)+p x(t) \alpha\left\{1-\frac{(1+\theta) p x(t)}{N}\right\}
$$

\section{RESULTS AND DISCUSSIONS}

Letting $x^{*}$ denote the steady state number of the infected individuals and substituting $x(t+1)=x(t)=x^{*}$ into equation (1), we have the condition $x^{*}$ should satisfy as

$$
x^{*}=p x^{*}\left[1+\alpha\left\{1-\frac{(1+\theta) p x^{*}}{N}\right\}\right]
$$

and by solving $x^{*}$ with respect to (2), we obtain

$$
x^{*}=\frac{\{(1+\alpha) p-1\} N}{\alpha(1+\theta) p^{2}} .
$$

Since $x^{*}$, the steady state number of the infected people, should be less than $N$ $\theta p x^{*}$, steady state number of those who can be infected, we have the condition $x^{*}$ should satisfy as

$$
x^{*} \leqq \frac{N}{1+\theta p} .
$$


If (4) is satisfied, the following inequality is also satisfied since $p$, the failure probability, is less than 1 :

$$
x^{*} \leqq \frac{N}{(1+\theta) p}
$$

which is derived by the condition that $1-\frac{(1+\theta) p x^{*}}{N}$ in equation (2) should be nonnegative.

Considering (3)-(5), we can draw a relationship between $p$ and $x^{*}$ typically as a graph, which is the combination of (3), curve-segment $\mathrm{AB}$, and $x^{*}=\frac{N}{1+\theta p}$ (, which is the part of (4)), curve-segment BC, as in Figure 1 on the $p-x^{*}$ plane.

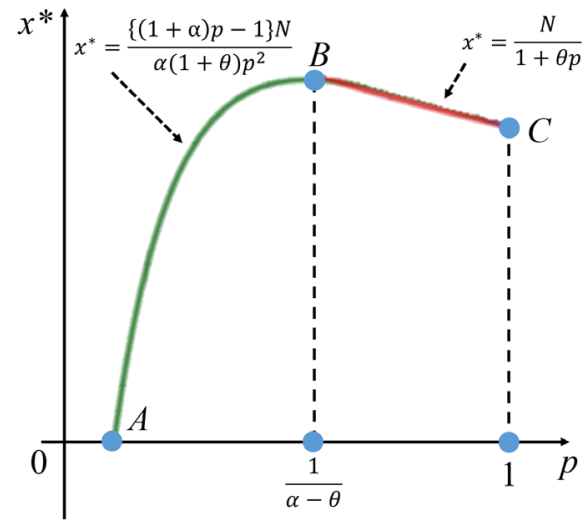

Figure 1 Relationship between failure probability and steady state number of the infected

\section{Proposition:}

The steady state number of the infected people, $x^{*}$, increases if the failure probability of PCR test decreases from 1

From this proposition, we can say that we should improve the accuracy of the PCR test much enough to reduce the number of the infected individuals since the improvement of the PCR test increases the number of the infected individuals at first.

\section{CONCLUSIONS}

The present study theoretically investigated the effects of improvement of the PCR test, to obtain the result that accuracy of the PCR test should be improved much enough to reduce the number of the infected individuals since the improvement of the PCR test increases the number of the infected individuals at first.

It is necessary to examine the robustness of our results in a more general framework that incorporates the economic activities. It is also of interest to investigate the compound effects of the PCR test, the vaccination and the treatment of COVID-19. We will conduct such analyses in the next paper. 


\section{REFERENCES}

Baker S. R., Bloom, N., Davis, S.J., Kost, K.J., Sammon, M.C. and Viratyosin, T (2020) The Unprecedented Stock Market Impact of Covid-19, NBER Working Paper Series 26945. Retrieved from https://doi.org/10.3386/w26945

Baker, S.R., Bloom, N., Davis, S.J. and Terry, S.J. (2020) COVID-induced Economic Uncertainty, NBER Working Paper Series 26983. Retrieved from https://doi.org/10.3386/w26983

Baker, S.R., Farrokhnia R.A., Meyer, S. Pagel, M. and Yannelis, C. (2020) How does Household Spending Respond to an Epidemic? Consumption during the 2020 Covid-19 Pandemic, NBER Working Paper Series 26949. Retrieved from https://doi.org/10.3386/w26949

Bandara, K. G. A. G. and Weerasooriya, W. M. R. B. (2021) A Study between the Taxpayers' Perception toward the Tax Policy Changes and the Tax Compliance in Sri Lanka: A Tax Relief in Response to the Impact of Covid-19 Epidemic, and its Implications, Business, Management and Economics Research, vol. 7(2), 52-64. Retrieved from https://doi.org/10.32861/bmer.72.52.64

Fujita, Y. (2020a) When Should We Start the Lockdown and How Long Should it be?, Modern Economy, 11, 1007-1011. Retrieved from https://doi.org/10.4236/me.2020.115075

Fujita, Y. (2020b) How Much should Government Compensate Firms for Suspension of their Businesses in ORDER to Fight Off the New Coronavirus?, Theoretical Economics Letters, 10, 600-606. Retrieved from https://doi.org/10.4236/tel.2020.103038

Fujita, Y. (2020c) How could We Prevent Spread of the Coronavirus without Deteriorating Economy?, Modern Economy, 11, 1280-1287. Retrieved from https://doi.org/10.4236/me.2020.117091

Fujita, Y. (2021a) Does Vaccinations Reduce the COVID-19 Infection?, Archives of Business Research, forthcoming. Retrieved from https://doi.org/10.14738/abr.98.10608

Fujita, Y. (2021b) Better than Nothing?: Consequence of Incomplete Treatment of COVID-19, Business Management and Economics Research, forthcoming. Retrieved from https://doi.org/10.5430/bmr.v10n3p11

Peto, J., et al. (2020) Stopping the Lockdown and Ending the Epidemic by Universal Weekly Testing as the Exit Strategy, Retrieved from https://ephg-covid19.org/

Ramadhanti, T., Singh, J. S. K. and Kularajasingham, J. (2021) Transactional and Transformational Leadership Styles as Predictors of Employee Performance during the Covid-19 Crisis and the Mediating Role of Organisational Culture, Business, Management and Economics Research, vol. 7(2), 39-51. Retrieved from https://doi.org/10.32861/bmer.72.39.51

Romer, P. (2020) Roadmap to Responsibly Reopen America, Retrieved from https://roadmap.paulromer.net/

Watanabe, T. (2020) The Responses of Consumption and Prices in Japan to the COVID-19 Crisis and the Tohoku Earthquake, Working Paper Series, CARFF-476. Retrieved from https://doi.org/10.7916/d8-qs4v-q792 